\title{
Explorando o Pensamento Computacional para Despertar Novos Talentos: Relato de uma Experiência
}

\section{Cristina Paludo Santos, Denilson Rodrigues da Silva, Giana Ferreira, Maria Gisele Flores da Silveira}

\author{
Universidade Regional Integrada do Alto Uruguai e das Missões (URI) \\ 98.802-470 - Santo Ângelo - RS - Brasil \\ paludo@san.uri.br,deniro@san.uri.br, giana.ferreira.s@gmail.com, \\ guiga.flores.silveira@hotmail.com
}

\begin{abstract}
This article describes an experiment conducted with high school girls from public and private schools in a city of Rio Grande do Sul, in order to stimulate computational thinking and to bring them closer to the computing area. The strategy used includes designing applications for smartphones using the MIT App Inventor educational platform. A description of the methodology applied and the results obtained is presented so that the experiment can be improved and replicated.
\end{abstract}

Resumo. Este artigo descreve uma experiência realizada com alunas do ensino médio de escolas públicas e privadas em um município do Rio Grande do Sul, com o intuito de estimular o pensamento computacional e aproximá-las da área de computação. A estratégia utilizada compreende a criação de aplicativos para smartphones utilizando a plataforma educacional MIT App Inventor. Uma descrição da metodologia aplicada $e$ dos resultados alcançados é apresentada de modo que a experiência possa ser aprimorada e replicada.

\section{Introdução}

Introduzir tecnologia e o pensamento computacional na sala de aula está se tornando cada vez mais importante visto a forte influência da tecnologia no cotidiano de crianças e jovens. Segundo Wing (2006) a constituição do pensamento computacional apresenta-se como uma das mais importantes contribuições da ciência da computação para o mundo, pois forma cidadãos com competências e habilidades necessárias para conviver e prosperar em um mundo cada vez mais tecnológico e global.

Em paralelo a tais reflexões, originam-se também debates e estratégias em prol da democratização do saber e do acesso das meninas/mulheres nas áreas científica e tecnológica visando quebrar estigmas e atingir o equilíbrio entre os gêneros no universo da Computação. Neste sentido, tanto o ensino de Computação nas escolas, quanto o fomento por uma maior inclusão das mulheres no segmento de Tecnologia da Informação (TI) têm sido uma preocupação crescente e gerando diversas ações que direcionam esforços no sentido de atender as demandas estabelecidas nestes cenários [Barcelos, 2012][Santos, 2016][Gomes et al., 2014][Wolber,2014] [Maciel, 2016].

O projeto Meninas Digitais Tchê Missões insere-se neste elenco de trabalhos. Acredita-se que ampliar a imagem mental dos jovens sobre o que significa ser um(a) cientista da computação pode ajudar a esclarecer detalhes sobre a área atraindo mais meninas e inspirando novos talentos. 
Para tanto faz-se uso de estratégias que permeiam diferentes abordagens incluindo ações voltadas ao público feminino no espaço da educação básica, onde as primeiras expectativas de futuro e planejamento de carreiras são construídas e, também no espaço do ensino superior promovendo a permanência daquelas meninas que já optaram por estas carreiras. Neste cenário, o principal objetivo é que tais ações sirvam como ponto de apoio à consolidação da imagem de que os espaços de Ciência e Tecnologia são também lugares onde as mulheres podem e devem ocupar.

Uma visão geral das ações no âmbito do projeto é apresentada nas próximas seções, destacando a metodologia empregada na execução do projeto (Seção 2), os resultados obtidos (Seção 3) e as considerações finais (Seção 4).

\section{Metodologia}

O presente projeto apresenta-se como um convite para refletir, se inspirar e aprender. Para tanto a metodologia adotada pelo projeto inclui atividades que visam evidenciar o potencial criativo, a competência, a inteligência e as habilidades que as meninas possuem para produzir tecnologias e não apenas para utiliza-las. As atividades incluem a promoção de discussões a respeito dos benefícios providos pela tecnologia para a sociedade, reflexões sobre a importância do papel da mulher nesse universo, geração de conhecimentos teóricos, práticos e operacionais. A Figura 1 descreve, em termos gerais, as principais atividades propostas.

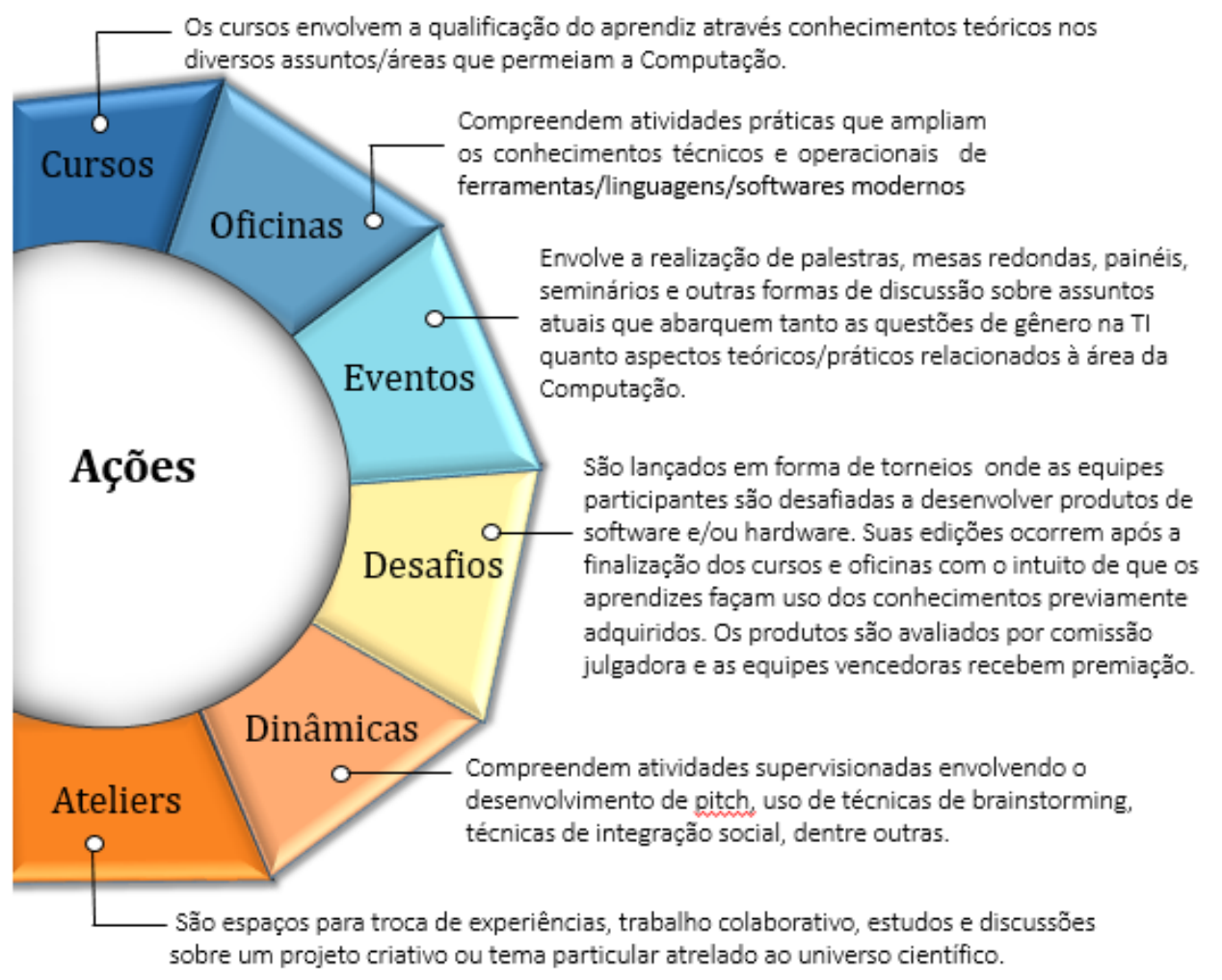

Figura 1. Ações desenvolvidas no projeto

O projeto foi executado na instituição proponente e contou com a participação de 54 meninas, do ensino médio, provenientes de escolas públicas e privadas do município de Santo Ângelo/RS. As meninas compunham 13 equipes, sendo que cada equipe contava com um 
professor da escola como responsável. Adicionalmente, atuaram no projeto 2 docentes da computação e 2 alunas do ensino superior.

A primeira atividade consistiu na promoção de um evento cuja programação contou com diversas atividades dentre as quais citam-se: (a) panorama sobre a participação das mulheres na área científica e tecnológica; (b) divulgação de outros projetos que visam estimular meninas para a área tecnológica; (c) breve descrição das habilidades adquiridas por acadêmicos dos cursos de Ciência da Computação e Sistemas de Informação; (d) atividades de integração; (e) utilização de Canvas para elucidação de ideias; dentre outras. Como parte das atividades também foram promovidas oficinas de Pitch e Brainstorming.

Após a realização do evento, iniciaram-se as atividades referentes ao curso e atelier de programação. O curso consistiu em duas etapas: inicialmente as alunas, que nunca haviam programado, tiveram aulas de programação em Android, através da plataforma APP Inventor uma ferramenta idealizada pelo Instituto de Tecnologia de Massachusetts (MIT), dos Estados Unidos em parceira com o Google, que contempla uma metodologia natural, fácil para aprender e que simplifica a parte de código mantendo a parte lógica. Em seguida, formaram equipes e passaram a contar diretamente com mentoras da área de tecnologia, que também serviram de papel-modelo para as jovens aprendizes. O curso teve duração de 8 semanas com carga horária total de 16horas/aula. Em paralelo ao curso também promoveu-se o atelier de programação que compreende um espaço descontraído para explorar ideias, trocar experiências e conhecimentos relacionados aos aspectos de programação. O atelier foi promovido semanalmente e de forma presencial.

Findadas as atividades inerentes ao curso de programação, as meninas participantes foram convidadas a participar de um desafio que buscou fomentar o interesse das jovens pela aplicação dos conhecimentos obtidos com vistas à criação de algo que fosse socialmente útil e pessoalmente gratificante. Para tanto foram três meses intensos de trabalho em que as equipes construíram um plano de negócios, desenvolveram um aplicativo para um problema social e um pitch para apresentar a ideia. A proposta do desafio foi "conceber um aplicativo voltado para a melhoria da qualidade de vida das pessoas". Participaram do desafio 5 equipes, totalizando 25 meninas. Os aplicativos desenvolvidos contemplaram os seguintes domínios de aplicação: (a) Orientações sobre a prática de exercícios físicos em academias ao ar livre; (b) Agenda diária para auxiliar os cuidadores de idosos; (c) Melhores ofertas nos supermercados da cidade; (d) Etiquetas sustentáveis para auxiliar a coleta seletiva de lixo e incentivar o uso de transporte coletivo e, (e) Biblioteca Virtual para agilizar o empréstimo de livros nas escolas. A Figura 2 apresenta a interface principal dos aplicativos desenvolvidos.
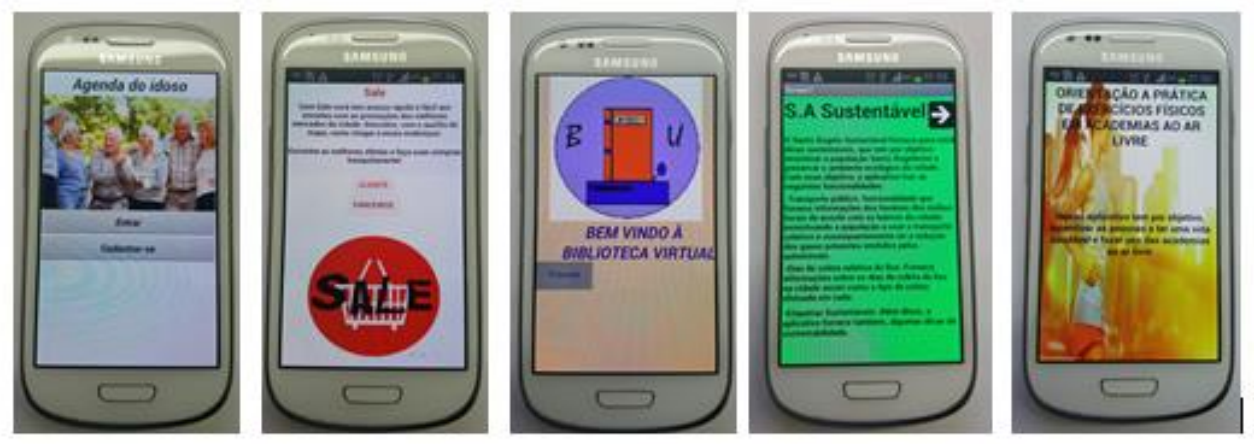

Figura 2. Aplicativos desenvolvidos pelas equipes participantes. 
O Desafio de Programação culminou em uma cerimônia de premiação e encerramento, onde os 3 melhores aplicativos foram premiados com troféus e medalhas (Figura 3). Um júri técnico avaliou o pitch e os aplicativos desenvolvidos.
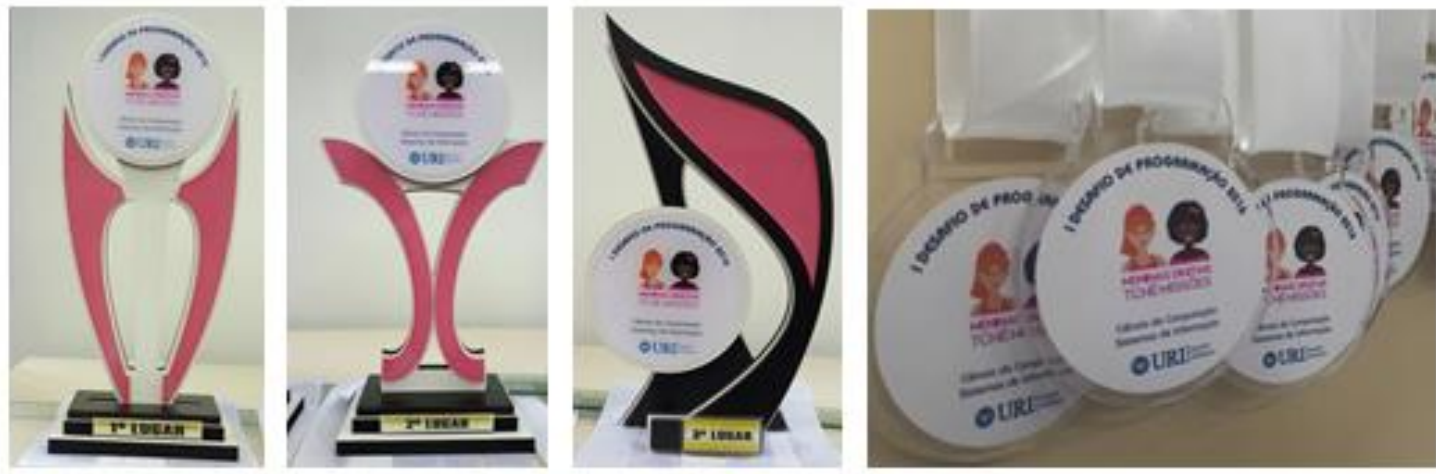

Figura 3. Troféus e Medalhas do I Desafio Meninas Digitais Tchê Missões

\section{Resultados Obtidos}

Os resultados desta experiência permitiram uma aproximação maior com a realidade das meninas no que se refere ao contato com a tecnologia. Todas as meninas participantes do projeto foram indagadas se já haviam tido contato ou sido incentivadas a programar antes de ingressar no Meninas Digitais. Dentre as declarações destacam-se: "Nunca. Eu nunca tive uma oportunidade dessas, mas estou amando tudo que estou aprendendo." (B.B, 16 anos); "Apenas coisas básicas de blogs. Nunca havia me aprofundado nesse assunto." (J.W, 17 anos); "Não. Está sendo uma experiência incrível." (R.X, 17 anos); "Não. Me chamou atenção justamente por isso." (R. G. $A, 18$ anos). A partir destas declarações percebe-se que há interesse das meninas pela área tecnológica, o que falta são iniciativas que oportunizem o contato das mesmas com este universo.

Destaca-se ainda que apenas 5 equipes participaram do Desafio. Esta questão foi averiguada e as meninas das demais equipes mencionaram que por estarem envolvidas com vestibular e provas do Enem, não puderam participar. Segundo elas se as atividades tivessem sido promovidas no $1^{\mathrm{o}}$ semestre do ano teriam maior disponibilidade de tempo. Estes dados permitiram a realização de ajustes no cronograma das ações a serem promovidas pelo projeto na sua segunda edição.

Evidencia-se ainda como resultado desta experiência o interesse das escolas em participar das novas edições do projeto. Inclusive outras escolas da cidade e região entraram em contato e demonstraram interesse das alunas em participar. Isso demonstra a boa repercussão do projeto nos espaços escolares.

Por fim, considera-se o projeto Meninas Digitais Tchê Missões uma iniciativa em processo de desenvolvimento e inovação que, contudo, já conta com resultados de sucesso, considerando os resultados obtidos na $1^{\text {a }}$ Edição, e um novo olhar da comunidade envolvida em relação ao tema Mulheres em TI. 


\section{Considerações Finais e Trabalhos Futuros}

Como forma de contribuir para mudar a realidade e a predominância masculina no mundo da ciência e tecnologia, são propostas ações por meio deste projeto com vistas a apresentar, engajar e aumentar o envolvimento das mulheres com a tecnologia. Acredita-se que esta iniciativa possa quebrar estigmas e contribuir para dirimir a reverberação do estereótipo de que Computação é "coisa de menino". Além do aspecto inclusivo, o projeto contribui na resolução de problemas sociais a partir das habilidades adquiridas.

Entende-se que criar culturas inclusivas pode ser uma abordagem bem-sucedida. Desvendar o feminino na construção do conhecimento vai ao encontro às preocupações de uma área ainda em construção no Brasil, mas fértil em abordagens e análises sobre a participação de mulheres na ciência e tecnologia.

\section{Referências Bibliográficas}

Wing, J. M. (2006) "Computational Thinking", In: Communications of the ACM, pages 33-35, March 2006/Vol. 49, No. 3, USA HANEY.

Barcelos, T. and Silveira, I. F. "Pensamento Computacional e Educação Matemática: Relações para o Ensino de Computação na Educação Básica”. In: XX Workshop sobre Educação em Computação, 2012, Curitiba. Anais do XXXII CSBC, 2012.

Maciel, C. and Bim, S. A. (2016) Programa Meninas Digitais - Ações para divulgar a Computação para meninas do ensino médio, In: Computer on the Beach 2016, Florianópolis, SC. pp.327-336, 2016.

Santos, Elisângela Ribas et al. Estímulo ao Pensamento Computacional a partir da Computação Desplugada: uma proposta para Educação Infantil/Stimulus to computational thinking: a proposal for elementary school. Revista Latino-americana de Tecnología EducativaRELATEC, v. 15, n. 3, p. 99-112, 2016.

Gomes, Wesckley Faria, et al. "Incentivando meninas do ensino médio à área de Ciência da Computação usando o Scratch como ferramenta." Anais do Workshop de Informática na Escola. Vol. 20. No. 1. 2014.

Wolber, D., Abelson, H. and Friedman, M. Democratizing Computing with App Inventor. Newsletter GetMobile: Mobile Computing and Communications - ACM, v. 18, n. October, p. 53-58, 2014. 